\title{
The effect of self-observation on the self-directed learning ability of nursing students: An experimental study
}

\author{
Dong-Hee Kim \\ Department of Nursing, Pusan National University, Busan, South Korea \\ Email: dongheekim@pusan.ac.kr
}

Received 9 July 2013; revised 25 August 2013; accepted 16 November 2013

Copyright (C) 2013 Dong-Hee Kim. This is an open access article distributed under the Creative Commons Attribution License, which permits unrestricted use, distribution, and reproduction in any medium, provided the original work is properly cited.

\begin{abstract}
Background: Patients expect nurses to be both technically competent and psychosocially skilled. Enhancing the quality of patient care and patient safety in healthcare settings has increased, resulting in limited opportunities for students to practice clinical skills in healthcare settings. Achieving competence in these skills is viewed as an essential task to be completed during the school curriculum. Objective: The purpose of this study was to evaluate the use of self-observation through cellular recordings as an adjunct to the clinical skills teaching of a blood sugar test to undergraduate nursing. Design: The research design consisted of pre- and post-test consecutive experimental design through a control group. Settings: This study targeted nursing students enrolled in baccalaureate programs running in Korea. Participant: The participants were 64 students including 34 for the experimental group and 30 for the control group. Methods: Those in the control group received standard teaching methods using lectures and skills classes and facilitated the use of self-study methods. Those in the experimental group received standard teaching using lectures and skills classes and facilitated use of cell phone recorded self-observation. The self-confidence of practicing a blood sugar test, satisfaction with the learning method, self-study participation, level of interest in nursing practice, and selfdirected learning ability were measured using questionnaires. Results: Significant between-groups differences were detected in self-confidence of practicing a blood sugar test $(t=2.067, p=0.043)$, satisfaction with the learning method $(t=2.818, p=0.044)$, selfstudy participation $\left(\chi^{2}=7.635, p=0.022\right)$, and average self-directed learning ability $(t=3.202, p=0.002)$. Conclusions: Self-observation through cellular phone recordings is an effective learning method as an adjunct to teach clinical skills.
\end{abstract}

Keywords: Cellular Phone Animation; Self-Confidence; Satisfaction; Learning; Nursing; Skill

\section{INTRODUCTION}

Good nurses are expected to have the necessary technical competences and knowledge. They should know what to do when problems occur and coordinate care efficiently. Several studies show that patients expect nurses to be both technically competent and psychosocially skilled [1].

In spite professional nurses should provide evidence based nursing practice in order to provide qualified nursing care, most novice nurses are not enough competent on clinical skills, which leads inappropriate care to patients and more burdens to other nurses by requiring to work additionally instead of the novice [2]. Generally nursing students are learning clinical skills in nursing laboratories first and more practice during the students' clinical practicum within health settings. However, enhancing quality and patient safety in health settings has increased, resulting in limited opportunities for students to practice clinical skills on health care settings. Moreover, it has decreased the ability to support novices and undergraduate students due to severe nursing shortages in health settings [3]. Therefore, providing sufficient experience for students to develop competence on the clinical skills has been more emphasized as an essential task to be completed during curriculum at the school.

Since 2006, the Korean Accreditation Board of Nursing has been accrediting nursing education programs in university with the goal of determining if nursing education has reached a level capable of producing nurses who can fulfill their social responsibilities. Competence on clinical skills is a core component required by Korean Accreditation Board of Nursing. Korean Accreditation Board of Nursing regulates the usage and set-up of students' self-practice availability such as running time, area 
of a nursing laboratory and practical instruments based on the number of students in order to encourage students' self-practice on clinical skills [4]. Such sentiments are shared by other countries such as England [5].

The effect of self-study including self-practice has been proved. Self-study using audiovisual learning tools had more effect than self-study using text or language on satisfaction with the self-study, self-competence on clinical skill performance, critical thinking ability and problem solving ability [6-8]. Especially using image of oneself as a visual learning tool helps to have a different reaction from observing someone else in the identical context. Comparing to an image of someone else produces less attention, while one pays much more attention with a self-image observation, and even provides strong source of self-efficacy [9]. Observing image of oneself performance is to provide clear information on how to best perform skills, and it strengthens beliefs in one's capability to memorize learned knowledge and performance for a long time $[10,11]$.

As students must have many opportunities to practice clinical skills themselves to become competent practitioner, it is doubtless that the teaching strategies should include learning environment where students enable themselves to find theoretical knowledge or information to enhance their skills, to analyze their skill problems, and to solve the problem based on evidences [12-14]. Self-directed learning ability is a method or process used by students to take the responsibility of their own learning, to determine their objectives and learning resources, to deal with appropriate activities and to evaluate their results with or without the help of instructors $[15,16]$. That's why educators have been seeking educational tools and activities which could induce student's actively involved learning rather than passive learning.

Educational media such as video is a useful tool for the teaching and learning of content [17], as cellular phone is popular and video function of the cellular phone is convenient and accessible. Providing students control over the screen encourages, the students become actively engaged in the learning process themselves and may stimulate concentration and motivation. Videos can provide an excellent medium to transmit knowledge to the viewer $[18,19]$. Video self-observation is a simple educational tool that can enhance student self-directed learning. From this perspective, we think that a video self-observation allows an active student involved learning methods to self-study with enhanced self-directed learning ability in the nursing laboratory.

Few numbers of studies have been conducted to determine whether self-observation interventions impacted on knowledge of performance [20], motor task performance [21] and physical assistive device use [22]. Most researches have been conducted in psychology and sports domain [23] and the findings have consistently demonstrated that self-observation improves skill performance. There has been little examination of the learner-controlled conditions for clinical skills. This is the first study providing the clinical utility with video self-observation using cellular phone in improving nursing student's selfdirected learning ability.

In summary, we investigated self-confidence on practicing blood sugar test, satisfaction with the learning method, self-study participation, interest in nursing practice and self-directed learning ability for two groups of nursing students learning various nursing practice skills.

\section{METHODS}

\subsection{Study Design}

This was a quasi-experimental study with a pre-post test design. The study was carried out between the $5^{\text {th }}$ and the $19^{\text {th }}$ of March, 2012.

\subsection{Participants}

Sixty-four students, aged 18 to 23 years, participated. This study targeted nursing students enrolled in baccalaureate programs throughout Korea. At the beginning of the study, the desired sample size was 64 (experimental group, $n=34$, control group, $n=30$ ), which was adjusted to 29 based on power $=0.8$, effect size $=0.75$, significance level $=0.05[8]$, and a $10 \%$ expected dropout rate during the academic year. Students were recruited from 2 universities located in distinct locations.

\subsection{Measures}

The instrument used to measure self-directed learning ability was the Korean self-directed learning ability, which was developed by the Korean Educational Development Institute [24]. This instrument consists of 40 typical Likert items; each Likert item ranged from 1 (not at all true of me) to 5 (extremely true of me). The instrument consisted of three subcategories, namely, learning plan, learning practice, and learning evaluation. The Cronbach's alpha of the instrument reported by Lee et al. (2003) was 0.93 [24]. In this study, the Cronbach's alpha was 0.88 , while those of the subscales ranged from 0.73 0.75 . The degree to which the students were self-confident about practice, the degree to which they were satisfied with the learning method, to what extent they participated in self-study, and their level of interest in nursing practice were measured using 10-point Likert scales.

\subsection{Ethical Consideration}

Written permission was received from the Pusan Na- 
tional University Hospital Clinical Trial Center for the study. Participation was entirely voluntary. Individual informed consent was obtained from each participant to ensure anonymity. A written summary of the study was given to those willing to participate in this study. Participants were free to refuse to participate or withdraw from the study at any time, and were informed that only the aggregate data would be reported. Participants were told that there would be no penalties for canceling their participation. Subjects agreed to the purpose of this study, voluntarily signed a form, and participated in the study. Participants were recruited from two universities.

\subsection{Procedure}

The intervention consisted of three phases: the learning skill phase, the self-study (intervention) phase, and the evaluation phase. Two instructors, not researchers, were involved in this study and they discussed the teaching process and educational materials of the blood test skill. They had simulated the teaching process prior to conducting the study. A blood test was chosen for two reasons. First, we wanted to conduct this research in a naturalistic environment. The time and period of the learning of the blood test skills were almost identical for the two universities belonging to the experimental and control groups. Second, a video camera enabled us to track student movements without disturbing their behavior.

During the learning skill phase that lasted approximately two hours, all of the participants of both the experimental and the control groups, participated in a lecture about performing a blood test and watched a video of a skilled model performing a blood test. This was followed by a demonstration by an instructor, and then students practiced under the instructor's supervision. Following learning of the skill, all students were asked to complete a questionnaire containing general characteristics and self-directed learning ability scales.

During the self-study phase, students in the experimental group were required to practice as a team consisting of three students; one student played the nurse role, another played the patient role, and the third student took photographs using his/her cellular phone. Everything was the same for the students in the control group with the exception that the third student observed the other two students without taking photographs. In the experimental group, while one student practiced the entire procedure of the blood test, the student who was taking the photographs ensured that the video contained only the student practicing and the environmental details that were related to the practice session. After finishing the practice session, the students in the experimental group were instructed to pay close attention and to try to identify what they did wrong or what was missing from the procedure while watching the video of themselves. This involved instructing the students to compare their performance to a standard procedure in the textbook or a video of a skilled model performing the procedure.

Students in the control group were also required to practice as a team; while one student performed the entire blood test procedure, a second student observed the entire practice session. After finishing the practice session, the students in the control group were instructed to discuss what they did wrong or what was missing from the procedure. This involved instructing the students to compare their performance to a standard procedure in the textbook or a video of a skilled model performing the procedure. Members of the control and experimental groups discussed problems they encountered during the practice session. The students took turns practicing. An instructor provided assistance when it was required by the students. After the self-study, the participants of both groups completed their self-study notes, which consisted of they had performed that day, what were improved during the practice, and which stages were still difficult to perform.

After a one-week intervention period, the participants were asked to complete the questionnaire.

\subsection{Data Analysis}

The collected data were coded and analyzed using SPSS version 18.0 for Windows (SPSS, Inc., Chicago, Illinois). Chi-squared and t-tests were used to confirm that there were no significant differences between the experimental and control groups on any general characteristics and pre-test score of self-directed learning ability. Descriptive statistics were utilized to evaluate the general characteristics of the participants. The data are given as the mean and standard deviations. A t-test was used to assess between-group differences in self-confidence of practice, satisfaction with the learning method, self-study participation, level of interest in nursing practice, and self-directed learning ability. Two-tailed $p$-values $<0.05$ were considered significant.

\section{RESULTS}

\subsection{Homogeneity the Experimental and Control Groups}

The homogeneity between the experimental and control groups is given in Tables 1 and 2 . No between-groups differences in general characteristics were detected. Regarding the self-directed learning scores, although no significant between-groups differences were detected, total self-directed learning ability scores of the control group were generally higher than those of the experimental group. 
Table 1. Homogeneity between the experimental and control groups $(n=64)$.

\begin{tabular}{|c|c|c|c|c|c|}
\hline \multicolumn{2}{|c|}{ Characteristics } & Exp. $(\mathrm{n}=34)$ & Con. $(n=30)$ & $\begin{array}{l}\chi^{2} / \text { Fisher } \\
\text { exact test }\end{array}$ & $p$ \\
\hline \multirow{2}{*}{ Gender } & Male & $1(2.9)$ & $0(0.0)$ & \multirow{2}{*}{ - } & \multirow{2}{*}{0.531} \\
\hline & Female & $33(97.1)$ & $30(100.0)$ & & \\
\hline \multirow{2}{*}{ Age } & 19 & $19(55.9)$ & $17(56.7)$ & \multirow{2}{*}{0.004} & \multirow{2}{*}{0.950} \\
\hline & $\geq 20$ & $15(44.1)$ & $13(43.3)$ & & \\
\hline \multirow{3}{*}{$\begin{array}{l}\text { Motive for course } \\
\text { selection }\end{array}$} & Having a job & $18(53.0)$ & $9(30.0)$ & \multirow{3}{*}{3.459} & \multirow{3}{*}{0.177} \\
\hline & Want to be a nurse & $8(23.5)$ & $11(36.7)$ & & \\
\hline & Others & $8(23.5)$ & $10(33.3)$ & & \\
\hline \multirow{2}{*}{$\begin{array}{l}\text { Satisfaction with } \\
\text { nursing }\end{array}$} & Good & $20(58.8)$ & $20(66.7)$ & \multirow{2}{*}{0.418} & \multirow{2}{*}{0.609} \\
\hline & Fair or not good & $14(41.2)$ & $10(33.3)$ & & \\
\hline
\end{tabular}

Table 2. Homogeneity of self-directed learning ability $(n=64)$.

\begin{tabular}{|c|c|c|c|c|}
\hline \multirow{2}{*}{ Characteristics } & Exp. $(\mathrm{n}=34)$ & Con. $(\mathrm{n}=30)$ & \multirow{2}{*}{$t$} & \multirow{2}{*}{$p$} \\
\hline & $\mathrm{M} \pm \mathrm{SD}$ & $\mathrm{M} \pm \mathrm{SD}$ & & \\
\hline Total self-directed learning ability & $3.44 \pm 0.42$ & $3.49 \pm 0.34$ & -0.478 & 0.634 \\
\hline Learning plan & $3.28 \pm 0.44$ & $3.20 \pm 0.42$ & 0.768 & 0.445 \\
\hline Learning practice & $3.52 \pm 0.51$ & $3.60 \pm 0.41$ & -0.697 & 0.488 \\
\hline Learning evaluation & $3.47 \pm 0.54$ & $3.57 \pm 0.50$ & -0.772 & 0.443 \\
\hline
\end{tabular}

\subsection{Self-Confidence of Practice and Satisfaction with Learning Method after Treatment}

The mean self-confidence effect on practice score for the experimental group and control group was $7.79 \pm 1.25$ and $7.13 \pm 1.31$, respectively $(t=2.067, p=0.043)$. The mean score of satisfaction with the learning method for experimental group was $8.00 \pm 1.29$, which was 0.87 points higher than the value of $7.13 \pm 1.17$ observed for the control group $(t=2.818, p=0.044)$ (Table 3).

\subsection{Self-Study Participation and Level of Interest in Nursing Practice after Treatment}

About $77 \%$ of the students in the experiment group reported that they actively participated in self-practice, while about $43 \%$ of the students in the control group actively participated in self-study $\left(\chi^{2}=12.051, p=\right.$ $0.001)$. No between-groups difference was detected in level of interest in nursing practice $\left(\chi^{2}=1.499, p=0.186\right)$ (Table 4).

\subsection{Comparison of Self-Directed Learning Ability}

Self-directed learning scores increased 0.20 points for students in the experimental group and decreased 0.03 points for those in the control group. There was a statistically significant difference between the experimental and control groups in self-directed learning ability scores $(t=3.202, p=0.002)$. Among the subcategories, statistically significant differences were observed between the experimental and control groups in learning practice $(t=$ $3.261, p=0.002)$ and learning evaluation $(t=3.634, p=$ 0.001) (Table 5).

\section{DISCUSSION}

As health care system is shifted to business-oriented model emphasizing the efficiency and productivity, the nursing quality level is very important factor to secure competitiveness for the organization hiring nurses, particularly for the hospital [25]. Moreover, current global economic recession seems to make the consideration of cost effectiveness in healthcare as essential as patient satisfaction and healthcare outcomes. Its environment requires that nurses are competent and independent professional practitioners throughout a better education [26].

The quality of the educational preparation of nurses and their commitment to lifelong learning are keys to the development of the nursing profession, and to improve healthcare outcomes, patients' satisfaction and cost effectiveness [27]. Self-directed learning is essential in both self-learning process and during the lifelong learning. Cadorin et al. (2012) reported that reflection on selfdirected learning ability of student before their graduation incorporates self-directed learning into the profes- 
Table 3. Self-confidence on practicing and level of satisfaction with the learning method after treatment $(n=64)$.

\begin{tabular}{cccccc}
\hline Characteristics & Exp. $(\mathrm{n}=34)$ & Con. $(\mathrm{n}=30)$ & \multirow{2}{*}{$t$} & \\
\cline { 2 - 3 } & $\mathrm{M} \pm \mathrm{SD}$ & $\mathrm{M} \pm \mathrm{SD}$ & & & \\
\hline Self-confidence on practicing & $7.79 \pm 1.25$ & $7.13 \pm 1.31$ & 2.067 & 0.043 \\
Satisfaction with the learning method & $8.00 \pm 1.28$ & $7.13 \pm 1.17$ & 2.818 & 0.044 \\
\hline
\end{tabular}

Table 4. Degree of self-study participation and level of interest in nursing practice after treatment $(n=64)$.

\begin{tabular}{|c|c|c|c|c|c|}
\hline \multirow{2}{*}{\multicolumn{2}{|c|}{ Characteristics }} & Exp. $(n=34)$ & Con. $(n=30)$ & \multirow{2}{*}{$\chi^{2}$} & \multirow{2}{*}{$p$} \\
\hline & & $\mathrm{n}(\%)$ & n $(\%)$ & & \\
\hline \multirow{2}{*}{$\begin{array}{l}\text { Self-study } \\
\text { participation }\end{array}$} & Actively & $26(76.5)$ & $13(43.4)$ & \multirow{2}{*}{12.051} & \multirow{2}{*}{0.001} \\
\hline & Neutrally or Passively & $8(23.5)$ & $17(56.6)$ & & \\
\hline \multirow{2}{*}{$\begin{array}{l}\text { Interesting in } \\
\text { nursing practice }\end{array}$} & Interested & $30(88.2)$ & $23(76.7)$ & \multirow{2}{*}{1.499} & \multirow{2}{*}{0.186} \\
\hline & Neutral or Not interested & $4(11.8)$ & $7(23.3)$ & & \\
\hline
\end{tabular}

Table 5. A comparison of self-directed learning ability $(n=64)$.

\begin{tabular}{|c|c|c|c|c|c|}
\hline \multirow{2}{*}{\multicolumn{2}{|c|}{ Characteristics }} & Exp. $(n=34)$ & Con. $(\mathrm{n}=30)$ & \multirow{2}{*}{$t$} & \multirow{2}{*}{$p$} \\
\hline & & $\mathrm{M} \pm \mathrm{SD}$ & $\mathrm{M} \pm \mathrm{SD}$ & & \\
\hline \multirow{3}{*}{$\begin{array}{c}\text { Total } \\
\text { self-directed } \\
\text { learning ability }\end{array}$} & Pre & $3.44 \pm 0.42$ & $3.49 \pm 0.34$ & \multirow[b]{3}{*}{3.202} & \multirow[b]{3}{*}{0.002} \\
\hline & Post & $3.64 \pm 0.36$ & $3.46 \pm 0.38$ & & \\
\hline & Difference & $0.20 \pm 0.27$ & $-0.03 \pm 0.31$ & & \\
\hline \multirow{3}{*}{$\begin{array}{l}\text { Learning } \\
\text { Plan }\end{array}$} & Pre & $3.28 \pm 0.44$ & $3.20 \pm 0.42$ & & \\
\hline & Post & $3.51 \pm 0.34$ & $3.31 \pm 0.47$ & \multirow[b]{2}{*}{1.122} & \multirow[b]{2}{*}{0.266} \\
\hline & Difference & $0.23 \pm 0.33$ & $0.11 \pm 0.48$ & & \\
\hline \multirow{3}{*}{$\begin{array}{l}\text { Learning } \\
\text { Practice }\end{array}$} & Pre & $3.52 \pm 0.51$ & $3.60 \pm 0.41$ & & \\
\hline & Post & $3.61 \pm 0.44$ & $3.46 \pm 0.41$ & \multirow[b]{2}{*}{3.261} & \multirow[b]{2}{*}{0.002} \\
\hline & Difference & $0.09 \pm 0.31$ & $-0.15 \pm 0.27$ & & \\
\hline \multirow{3}{*}{$\begin{array}{l}\text { Learning } \\
\text { evaluation }\end{array}$} & Pre & $3.47 \pm 0.54$ & $3.57 \pm 0.50$ & & \\
\hline & Post & $3.66 \pm 0.51$ & $3.40 \pm 0.48$ & \multirow[b]{2}{*}{3.634} & \multirow[b]{2}{*}{0.001} \\
\hline & Difference & $0.19 \pm 0.41$ & $-0.18 \pm 0.39$ & & \\
\hline
\end{tabular}

sional continuum with clarifying school's contribution in development self-directed learning [28]. In this study, we focused on clinical skills laboratories since self-confidence on clinical skills decrease clinical practice stress but increase clinical skill performance and clinical competency during clinical practicum, and even it reflects on clinical competency for novice [11,29-31]. Regarding clinical skill performance, there was a positive relation between self-directed learning ability and the clinical performance in medical faculty [32].

Self-observation seems to relate with positive self-review which improves the rate of a behavior that is below its desired level by increasing of rates of performance. In this study, self-directed learning score increased and especially subcategories of learning practice and learning evaluation were statistically significant differences observed compared to control group. Many sports programs use positive self-review rather than video feedback to improve athletes' performance [9]. Moreover, there are some researches demonstrating the benefits of self-observation such as learning models [33]. Some studies have found changes in self-efficacy that correlate with changes in skill acquisition after viewing self-model videos versus a comparison condition [34].

There have been conducted studies to examine the effect of audiovisual technologies on nursing skill. Wolley and Jarvis (2006) suggested that CCTV and digital recording technologies enable to support learning skills applying the cognitive apprenticeship model. They reported that considerable investment including equipment 
cost, technical expertise and time required at various points within the class to integrate and effectively deliver the model within the curriculum [35]. While the video self-observation using cellular phone need not audiovisual technician whose maintenance and operation cellular phone since students already know how to record movement. Kang (1996) and Yeun (1999) examined the effectiveness of videotape-record method in fundamental nursing skill education $[8,30]$. Even though using videotape-record learning is effective to improve student's skill, it can be time consuming activity. While the video self-observation using cellular phone need not overly extend the typical time required waiting time to turn. Students enable to arrange their time and regulate the frequency of the skill practices.

The mean self-confidence on practice score for experimental group was much higher in this study (7.79) than the Kang's (1996) study rating 4.34 whereas similar to Yeun's (1999) study rating 7.60 [8,30]. Most students reported they were actively participated in self-practice and the mean satisfaction with the learning method for experimental group was higher than the control group in this study. Considering these results we suggest that video self-observation using cellular phone method is useful to increase satisfaction with the learning method, self-study participation, interesting in nursing practice and self-directed learning ability in nursing.

The study seemed to suggest that self-observation is effective on self-confidence on practice, satisfaction with the learning method, self-study participation, interesting in nursing practice and self-directed learning ability, but a larger study is required to investigate this further. Furthermore, there appears to be a need for a more detailed insight questionnaire able to measure the qualitative aspects of self-confidence on practice, satisfaction with the learning method, self-study participation, interesting in nursing practice. Future research in video self-observation could use the evaluation of nursing practices.

Accuracy of the skill may be an issue in this study. We could compare to the actual score to measure accuracy of the blood test skill because control group and experimental group had different time schedule to examine. We recommend that further study examining if video selfobservation using cellular phone effect to increase accuracy of the skill or not should be conducted. However, we believe that the process of video self-observation using cellular phone itself can be effective. The recording and analysis of experience enable the student not only to develop skills by using a reflective cycle to guide the process but also to explore the nuances of practice, their own perceptions and interpretations of these experiences [36]. Therefore we also recommend considering video self-observation using cellular phone as a possible way to encourage practitioners enable to examine their ac- tions.

\section{CONCLUSION}

As technology develops rapidly, clinical environments have been changing and are getting more complex. Nurses should be able to focus on these changing clinical conditions and deal with these changes by finding and using available resources, performing appropriate activities such as learning, practicing, and applying themselves to the clinical setting. This means that nurses who are incapable of directing their own learning will not operate these changes in complex health settings [37]. Although self-modeling has been an effective means for modifying behaviors in a variety of settings, little research has been completed on nursing performance. The purpose of this study was to test the effectiveness of self-observation on self-study participation using a blood sugar test and to explore the level of satisfaction regarding one's performance and the self-study participant. Results indicated that self-observation may contribute to an increase in selfdirected learning ability. There were significant differences between the two groups in self-confidence in performing the blood sugar test, satisfaction with the learning method, and self-study participation. In conclusion, self-monitoring through cellular phone recording is an effective adjunct learning method for clinical skills.

\section{ACKNOWLEDGEMENTS}

This work was supported by a 2-Year Research Grant of Pusan National University.

\section{REFERENCES}

[1] Van der Elst, E., Dierckx de Casterlé, B. and Gastmans, C. (2012) Elderly patients' and residents' perceptions of the good nurse: A literature review. Journal of Medical Ethics, 38, 93-97.

http://dx.doi.org/10.1136/medethics-2011-100046

[2] Park, J.H. and Chun, I.S. (2008) The lived experience of newly employed nurses: Phenomenological study. Journal of Qualitative Research, 9, 99-110.

[3] Somerville, B., Mcllwrath, M., Johnson, M., Langdon, R. and Jones, W. (2000) A collaborative approach to developing nursing skills to meet service needs. Collegian, 7 , 28-33. http://dx.doi.org/10.1016/S1322-7696(08)60374-1

[4] Korean Accreditation Board of Nursing Education (2012) Nursing education accreditation standards. http://www.kabon.or.kr/eng/kabon02/index02.php

[5] United Kingdom Central Council for Nursing, Midwifery and Health Visiting (2001) Standards for specialist community education and practice. UKCC, London.

[6] Batcheller, A., Brennan, R.T., Braslow, A., Urritia, A. and Kaye, W. (2000) Cardiopulmonary resuscitation performance of subjects over forty is better following halfhour video self instruction compared to traditional four- 
hour classroom, Resuscitation, 43, 101-110. http://dx.doi.org/10.1016/S0300-9572(99)00132-X

[7] Kim, H.S., Oh, K.S. and Ryu, J.I. (2002) Perception of professional ability between entry and graduation of RNBSN program. Journal of Nursing Query, 11, 99-113.

[8] Yeun, E.J. (1999) Effectiveness of video-record method on fundamental nursing skill education: Focus on intramuscular injection practice. Journal of Korean Academic Society of Nursing Education, 5, 86-96.

[9] Dowrick, P.W. (1999) A review of self-monitoring and related interventions. Applied and Preventive Psychology, 8, 23-39. http://dx.doi.org/10.1016/S0962-1849(99)80009-2

[10] Bandura, A. (1997) Self-efficacy: The exercise of control. W.H. Freeman, New York.

[11] Kim, Y.H. (2008) Satisfaction with evaluation method for fundamental nursing practice skill education through cell phone animation self-monitoring and feedback: Focus on foley categorization. Journal of Korean Academy of Fundamentals of Nursing, 15, 134-142.

[12] Baxter, P., Akhtar-Danesh, N., Valaitis, R., Stanyon, W. and Sproul, S. (2009) Simulated experiences: Nursing students share their perspectives, Nurse Education Today, 29, 859-866. http://dx.doi.org/10.1016/j.nedt.2009.05.003

[13] Kim, D.H., Park, J.Y. and Lee, N.Y. (2012) Factors influencing problem solving ability among nursing students. Journal of the Korean Data Analysis Society, 14, 15511564.

[14] Youn, M.S. and Cho, J.Y. (2010) Experience and confidence on clinical nursing performance in delivery room of nursing students according to the clinical practice settings. Journal of the Korean Data Analysis Society, 12, 909-922.

[15] Knowles, M.S. (1975) Self-directed learning: A guideline for learners and teacher. Follett Publishing, Chicago.

[16] Spencer, J.C. and Jordan, K.R. (1999) Learner centered approach in medical education. British Medical Journal, 318, 1280-1283.

http://dx.doi.org/10.1136/bmj.318.7193.1280

[17] Fleming, S.E., Reynolds, J. and Wallace, B. (2009) Lights... camera... action! A guide for creating a DVD/Video. Nurse Educator, 34, 118-121. http://dx.doi.org/10.1097/NNE.0b013e3181a0270e

[18] Lee, J., Boyd, R. and Stuart, P. (2007) Randomized controlled trial of an instructional DVD for clinical skills teaching. Emergency Medicine Australasia, 19, 241-245. http://dx.doi.org/10.1111/j.1742-6723.2007.00976.x

[19] Zwirn, E. (2005) Using media, multimedia, and technology rich learning environments. In: Wilhelm, T., Ed., Teaching in Nursing: A Guide for Faculty, Elsevier, St. Louis, 377-396.

[20] Wulf, G., Raupach, M. and Pfeiffer, F. (2005) Self-controlled observational practice enhances learning. Research Quarterly for Exercise and Sport, 76, 107-111.

[21] Wu, W.F.W. and Magill, R.A. (2011) Allowing learners to choose: Self-controlled practice schedules for learning multiple movement patterns. Research Quarterly for Exercise and Sport, 82, 449-457. http://dx.doi.org/10.1080/02701367.2011.10599777
[22] Hartman, J.C. (2007) Self-controlled use of a perceived physical assistance device during a balancing task. Perceptual and Motor Skills, 104, 1005-1116. http://dx.doi.org/10.2466/pms.104.3.1005-1016

[23] Ran, N. and McCullagh, P. (2003) Applied research selfmodeling: Influence on psychological responses and physical performance. The Sport Psychologist, 17, 220-241.

[24] Lee, S.J., Jang, Y.K., Lee, H.A. and Park, K.E. (2003) Study on the development of life-skills: Communication, problem solving and self-directed learning. Korean Educational Development Institute, Seoul.

[25] Registered Nurses' Association of Ontario (2007) Professionalism in nursing. Registered Nurses' Association of Ontario, Toronto.

[26] Baumann, S.L. (2009) Improving the profession of nursing in Slovenia. Nursing Science Quarterly, 22, 369-370. http://dx.doi.org/10.1177/0894318409344757

[27] Dornik, E., Vidmar, G. and Zumer, M. (2005) Nursing education in Slovenia and its impact on nurses publishing in their professional journal. Education Today, 25, 97203.

[28] Cadorin, L., Suter, N., Dante, A., Williamson, S.N., Devetti, A. and Palese, A. (2012) Self-directed learning competence assessment within different healthcare professionals and amongst students in Italy. Nurse Education in Practice, 12, 153-158. http://dx.doi.org/10.1016/j.nepr.2011.10.013

[29] An, H.G. (2006) The relationship between stress of clinical practice and mental health in nursing students. Journal of the Korean Data Analysis Society, 8, 2249-2264.

[30] Kang, K.S. (1996) Effectiveness of video-record method on fundamental nursing skill education. Journal of Korean Academy of Fundamentals of Nursing, 3, 278-288.

[31] Gerrish, K. (2000) Still fumbling along? A comparative study of the newly qualified nurses' perception of the transition from student to qualified nurse. Journal of $A d-$ vanced Nursing, 32, 473-480. http://dx.doi.org/10.1046/j.1365-2648.2000.01498.x

[32] Shokar, G.S., Shokar, N.K., Romero, C.M. and Bulik, R.J. (2002) Self-directed: Looking at outcomes with medical students. Family Medicine, 34, 197-200.

[33] Adams, J. (1986) Use of the model's knowledge of results to increase the observer's performance. Journal of Human Movement Studies, 12, 89-98.

[34] Bradley, R.D. (1993) The use of goal-setting and positive self-modeling to enhance self-efficacy and performance for the basketball free-throw shot. Ph.D. Thesis, University of Maryland, College Park.

[35] Wolley, N.N. and Jarvis, Y. (2006) Situated cognition and cognitive apprenticeship: A model for teaching and learning clinical skills in a technologically rich and authentic learning environment. Nurse Education Today, 27, 73-79. http://dx.doi.org/10.1016/j.nedt.2006.02.010

[36] Shardlow, S. and Doel, M. (1996) Practice learning and teaching. Macmillan, Basingstoke.

[37] O'Shea, E. (2003) Self-directed learning in nursing education: A review of the literature. Journal of Advanced Nursing, 43, 62-70. http://dx.doi.org/10.1046/j.1365-2648.2003.02673.x 